\title{
Creating Creative Technologists: Playing With(in) Education
}

\author{
Andy M. Connor, Stefan Marks \& Charles Walker
}

\begin{abstract}
Since the industrial revolution, the organization of knowledge into distinct scientific, technical or creative categories has resulted in educational systems designed to produce and validate particular occupations. The methods by which students are exposed to different kinds of knowledge are critical in creating and reproducing individual, professional or cultural identities. ("I am an Engineer. You are an Artist"). The emergence of more open, creative and socialised technologies generates challenges for discipline-based education. At the same time, the term "Creative Technologies" also suggests a new occupational category ("I am a Creative Technologist").

This chapter presents a case-study of an evolving 'anti-disciplinary' project-based degree that challenges traditional degree structures to stimulate new forms of connective, imaginative and explorative learning, and to equip students to respond to a changing world. Learning is conceived as an emergent process; self-managed by students through critique and open peer review. We focus on 'playfulness' as a methodology for achieving multi-modal learning across the boundaries of art, design, computer science, engineering, games and entrepreneurship. In this new cultural moment, playfulness also re-frames the institutional identities of teacher and learner in response to new expectations for learning.
\end{abstract}

Keywords. Playfulness, play, creative technologist

\section{Introduction}

The Bachelor of Creative Technologies (BCT) degree is offered by Colab, a unique academic unit at Auckland University of Technology. The unit is a research-teaching nexus or "collaboratory" at the intersection of four existing Schools (Art \& Design, Communications \& Media Studies, Computer \& Mathematical Sciences, and Engineering) in the Faculty of Design and Creative Technologies. The goal of Colab is to develop new experimental alliances, research collaborations and learning experiences across these overlapping disciplines. Its researchers, students and stakeholders are encouraged to imagine, construct and navigate rapidly changing social, economic, technological and career environments.

The BCT is seen as a key enabler of this goal. The flexible and experimental projectorganised curriculum draws on philosophical notions of play, community and interaction to promote divergent thinking and to break, blur or transcend normative disciplinary boundaries [1]. In this context, we use the term Creative Technologies as to refer to a multiplicity of design, communication, computing, engineering, entertainment, and manufacturing media; employed to produce ideas, intellectual property and artefacts that characterise the outputs of emerging occupations and professions operating across a wide range of entrepreneurial creative industries contexts.

Whilst the degree embodies this definition, at another level it also represents a vehicle for the authors' ongoing search for creative, hypothesis-driven or inquiry-based learning methodologies that address Boyer and Mitgang's impassioned call for; 
"a new educational language ... driven by the conviction that the standards used to evaluate performance should be organized not so much around blocks of knowledge ... as around modes of thinking: the discovery, integration, application and sharing of knowledge" [2].

However, the main weakness of Boyer \& Mitgang's thesis is that it is pitched at the level of educational meta-theory; leaving individual development, motivations and relationships among people in real learning environments relatively unexamined. In designing the BCT curriculum, we sought to develop new "modes of thinking" that shift the traditional focus from teaching-by-transmission to a more socialised engagement with learning through creativity, collaboration and play. More specifically, we came to identify a playful approach to "discovering, integrating, applying and sharing" different kinds of knowledge - whether theoretical, technical, intuitive, practical, emotional or organisational - within crossdisciplinary learning environments. Whilst there is an emphasis on playfulness as an approach to create curious learners, this is balanced through a combination of structured and semi-structured learning. The first year of the degree purposefully selects students from different backgrounds and introduces basic programming, electronics, digital media and artistic practices in parallel to guided projects that integrate this knowledge across the diverse student body. This pattern is modelled throughout the degree, with the expectation that skills and knowledge developed in more formal components will be integrated into the studio projects undertaken.

We adopt an approach that embeds the spirit of play as defined by Millar [3] who argues that play is characterised as the shifting of the frame of activity from one domain to another, in particular the concept of play shifts activities from "reality" to a new "play-specific spacetime" with its own protocols. We also consider the definition of play given by Gordon and Esbjörn-Hargens [4] who expand this to include playfulness, the attitude that shakes off constraints and enables any activity to become play. The removing of such constraints allows students to learn in the play-specific space-time in a free and explorative manner, before then translating the knowledge and skills back to reality.

The ability to think and act outside of everyday constraints is pivotal in the development of Creative Technologists, who are required to find solutions to problems in a given reality and may find these solutions through a process of projecting their knowledge into a unique space through a similar shift from reality.

\section{The Spectrum of Play(fulness)}

Play has historically been a considerable focus of research in terms of understanding early education and childhood development, particularly as a means of developing creativity $[5,6]$. Russ argues that "Play skills and creative abilities help lay the foundation for a child's cognitive and emotional functioning and for a happy and meaningful adult life" [7] yet this begs the question why the focus on play in early childhood education is not continued into secondary and post-secondary education.

Rice has considered the role of play in post-secondary education suggests that "playful learning can be effective in motivating and improving student engagement, promoting creative thinking towards learning and developing approaches towards multi-disciplinary learning" [8]. Rice also observes that a playful approach towards learning and knowledge 
can facilitate ontological change within students. Such change is pivotal in assisting students to transcend normative disciplinary boundaries and reach their full potential as creative practitioners. As such, the adoption of play as a learning approach in combination with the development of a safe space that encourages risk taking and exploration is core to the pedagogical foundations of the degree.

While less attention has been paid to playfulness in adults, it is recognised to exist. For example, adults have been known to evidence playful behaviour even when they are engaged in practical or serious activities [9] as well as in the workplace [10]. This perhaps indicates that such activities might be accomplished quite playfully at times [11]. Caldwell [12] argues that lifelong play is a means of continuing transformation and Göncü \& Perone [13] have found that play and improvisation amongst adult learners fosters community as a result of developing dialogue, trust, reciprocity, sharing and negotiation.

Play, creativity and community are linked through the common ground of divergent thinking, a process that generates a variety of ideas and associations to a given problem. There is a variety of research evidence that suggests that play facilitates both divergent thinking and creativity [7], both of which are considered to be of considerable importance in the development of Creative Technologists. Our approach to implementing a playful educational paradigm also draws on an understanding of cognitive development. Again, much of the research in this field draws on childhood development which has emerged as an ongoing area of interest since the work of Piaget [14]. Bruner [15] argues that a child of any age is capable of understanding complex information and explains how this is possible through the concept of the spiral curriculum. This involves the structuring of information so that complex ideas can be taught at a simplified level first, and then re-visited at more complex levels later on to lead to children being able to solve problems by themselves. Bruner also proposes that learners construct their own knowledge and do this by organising and categorising information using a coding system [16]. Bruner believes that the most effective way to develop a coding system is to discover it rather than being told it by the teacher. The concept of discovery learning implies that students construct their own knowledge for themselves. Meyer and Land [17] also acknowledge that this process of change through learning is also a process of loss, in the sense that gaining new insights on the world, may involve a 'loss' of one's old self.

Many authors have proposed different development phases that can be mapped to an ability to process complex information in different ways, typically divided into a number of phases. The full spectrum model divides the development of an individual into four phases, preconventional (prepersonal), conventional (personal), post-conventional (postpersonal) and post-post conventional / transcendent (transpersonal). Cook-Greuter [18] suggests that approximately $90 \%$ of the adult population function within the first two tiers of development and that current conventional adult development is a linear, rational model of reality through which individuals can achieve abstract or formal operations. Cook-Greuter goes on to suggest that post-conventional "goes beyond the modern, linear-scientific Western mindset and beyond the conventions of society by starting to question the unconsciously held beliefs, norms and assumptions about reality acquired during socialization and schooling".

Gordon and Esbjörn-Hargens [4] provide an insight to the nature of play in terms of such a developmental framework. They describe eight "play selves" in relation to both a four-tier 
model of development and the rhetorics of play discussed by Brian Sutton-Smith [19]. This comparison is reproduced in Table 1.

For Creative Technologists to be able to create new technological paradigms, they need to be able to function at the post-personal or trans-personal level. Trans-personal theory argues that these higher levels, which involve experiences of connectedness with phenomena considered outside the boundaries of self, can engender the highest human qualities, including altruism, creativity, and intuitive wisdom [20].

Table 1. Play Rhetorics in the Developmental Model [4]

\begin{tabular}{|l|l|l|}
\hline Developmental Stage & Play Rhetoric & Play Self \\
\hline Transpersonal & Play as frivolity & $\begin{array}{l}\text { Unitive Player } \\
\text { Dynamic Player }\end{array}$ \\
\hline Postpersonal & $\begin{array}{l}\text { Play as self } \\
\text { Play as imagination }\end{array}$ & $\begin{array}{l}\text { Complex Player } \\
\text { Sensitive Player }\end{array}$ \\
\hline Personal & $\begin{array}{l}\text { Play as self } \\
\text { Play as progress } \\
\text { Play as identity }\end{array}$ & $\begin{array}{l}\text { Status Player } \\
\text { Ordered Player }\end{array}$ \\
\hline Prepersonal & $\begin{array}{l}\text { Play as power } \\
\text { Play as fate }\end{array}$ & $\begin{array}{l}\text { Aggressive Player } \\
\text { Magical Player }\end{array}$ \\
\hline
\end{tabular}

Whilst a number of mature students are accepted into the programme each year, the majority of applicants are recent school leavers - many of whom have progressed through high school to obtain the New Zealand National Certificate of Educational Achievement (NCEA) at a sufficient level to gain entrance to University. NCEA is a standards based system where students accumulate credits on the basis of demonstrating that they have met predefined standards of achievement [21]. Critics of the NCEA approach have argued that the standards based approach has both pedagogical and educational concerns because there is no distinction between academic and vocational subjects in assessment methods, and Unit Standards do not motivate students to excel and extend themselves [22].

Proponents of the NCEA approach suggest that NCEA allows students and educators to focus on interpersonal relations, critical thinking skills, self-evaluation, risk-taking, individual leadership, teamwork, innovation and creativity [23]. Experiential and anecdotal evidence suggests that if anything, the NCEA is variable and produces students with a wide range of capabilities. With that in mind, the educational strategies deployed in the BCT programme focus initially on developing play and playfulness at the prepersonal level as a levelling process to assist all students to learn about multiple perspectives and disciplines, before progressing through different play rhetorics to aim to develop students' full potential.

The transition from high school to University is a significant life change that often results in students feeling out of place and unsure of their own competencies. As a result, the behaviour of students is such that they tend to adopt the Magical "play self" that is characterised by feelings of confusion and anxiety arising from dealing with the complexity of the new environment. Incoming students typically have no sense of their potential or capability, which results in some students undertaking overly-optimistic projects whilst others err on the side of caution. 


\section{The Space of Play}

The BCT is, in part, conceived as a creative inquiry-led undergraduate degree with the characteristics of a postgraduate research programme [24]. We emphasise interactive, project-oriented learning in which students are engaged and active participants. As a result, their learning experience is one of personal transformation that has the potential to produce graduates that function at the postpersonal and transpersonal levels. Team-based project work also enhances opportunities for peer review and co-creation.

At another level, it is the hybrid nature of the learning space in which the BCT is 'played out' that is key to how students engage with the transdisciplinary nature of the emerging Creative Technologies domain. We combine aspects of the artist's studio, the design atelier, the workshop, and the laboratory in to a unique active learning space. The first two combine personal inspiration, 'creative freedom' and the specific conditions of creative practice, the lab focuses on the scientific simulation of reality and the workshop is concerned with engineering and the production of the world. Thus the programme encourages students to playfully imagine, model and make connections, relationships or associations between ideas and phenomena under investigation; not to find an answer, but rather a starting point or an "attitude" $[25,26]$. Like "the arena, the card-table, the magic circle, the temple, the stage, the screen, the tennis court, [and] the court of justice", the learning place can be seen as "a playground, a place where 'special rules obtain', dedicated to the performance of an act apart" [1].

It is important to emphasise that this "performance .... apart" does not denote a closed or self-contained system, but relies on frequent interaction, intervention or dynamic interplay with the everyday world. Neither does our focus on play undermine the importance of real tools, media, and context in human development. Following Piaget, we recognise that "knowledge is experience that is acquired through interaction with the world, people and things" [27]. We also acknowledge an historical trajectory of collaborative learning spaces; from Dewey's concepts of "continuity and interaction" [28], Vygotsky's "active participation in the acquisition of knowledge" [29], Wenger's components of "meaning", "practice", "community" and "identity" [30] and Abbott's [31] "ecologies of practice".

This distance between the everyday world and the world of play does not prevent play from being real, but enables it to be real. Like art, play both refers to and distances us from the world at the same time. We play against the world - and with it. Thus, our learning place is both, fake and real, ordinary and artificial, fun and serious [32]. Again, like art, play is a process which exists only as experience. Both activities refer to and distance themselves from the world at the same time. Art is playing against, and with, the world; using material, objects and relations of the world, but aiming at a quality beyond it. From this point of view, there must be a distance between learners and the real world, even as they work on real world problems to bring works into existence, beyond the studio, and into everyday life.

For us, play and learning are connected to each other, but the relationship is not as direct as is sometimes assumed. For educators, this can be challenging. Players can, and do, decide what is play and what is not. Play is most free when it is least staged. External restrictions, aims, or even learning outcomes imposed on play can destroy it. Indeed, even those who purport to be in favour of play in education often seem to rely on "a Mary Poppins type of argument. A spoonful of sugar and the medicine goes down!" [33]. 
We propose to resolve these apparent contradictions by locating our learning environment in a conceptual third place. It is not a little bit real world and a little bit space apart; it is fully real in the sense that play is real; it is taken seriously while the game is being played. The learning environment is an individual place and a collective place. It creates experiences that are visited repeatedly, cyclically; while at the same time, no experience is ever the same twice. It is a place people want to reach and a place they want to leave; a real place, a virtual space and a journey.

Students are open to this new play-space. In recent years, the students entering the programme can increasingly be referred to as "digital natives"; a term coined by Prensky [34] to define the differences between generations in terms of their attitudes toward virtual environments and digital tools. As a result, a more blended approach has been developed that utilises traditional Studio and classroom methods combined with online discussion and Web 2.0 tools such as blogs, wikis, social networking and learning management tools.

Students are required to use online tools to assist their own learning, starting with the development of a blog in the first year [35] to enhance education by encouraging reflective practice. Beale [36] argues that blogging provides advantages in terms of both pedagogical and social perspectives. For example, it has been observed that blogging produces a sense of community amongst the students because they can read and comment on other students postings. The result is that they can learn from both reflecting on their own experiences and from the insights of their peers. While the role of the blog is primarily to develop a reflective habit, it stealthily introduces processes of collection, selection and critical discernment. Beale [36] also argues that the fact that students can see the sort of activities done by other students there is transparency in terms of the amount of work that is required as well as the quality of work being produced. Because others can also see their level of activity or inactivity, peer pressure should exert an influence and encourage them to maintain a degree of selectivity in terms of how the students present their work and their reflections.

One of the aspirations of the course is to generate an environment where both student and teacher construct the learning agenda in partnership. A key element of this construction is a continuous dialogue that is achieved through frequent critique sessions (or "crits").

Questioning is often used to guide student thinking. A particular technique (or style of questioning), gleaned from educational literature [37] is used - the reflective toss. The purpose of the reflective toss is to allow the lecturer to interpret the meaning of a student statement but ensure that the student continues to elaborate their underlying thinking. In such an environment, the traditional transmissive view of education is replaced with one where the role of the lecturer is not to supply information to the students but to guide and facilitate their learning.

The overall goal of the lecturer-as-facilitator is to move the focus of student learning away from simply remembering facts, towards some form of higher learning, such as the understanding of underlying principles. Such a goal is appropriate for a programme that aims to develop graduates with competency at the higher level skills of analysis, synthesis and evaluation associated with postpersonal and transpersonal development. In order to achieve this development the students in the programme are guided through a range of projects that are designed around different rhetorics of play with a view to guiding students through different stages of personal development. 
This playful student-centred learning environment aims to develop the learner's capacity to be self-directed. Given rapid change, the continuous creation of new knowledge, and an ever-widening access to information, we endeavour to let students identify and choose their own challenges, define their own areas of interest, decide on methods, focus and direction, form project teams, formulate research questions, design their own research plan, and develop knowledge of practices in the particular field or area [38]. All of this is intended to stimulate connective, imaginative and explorative learning. In the absence of fixed or predetermined outcomes, students are challenged to learn, to analyse and to critically discuss their own work and that of others, e.g. by regularly conducting open peer reviews of project work. Learning happens not only through participation, by doing, but also by analysing and critiquing the work of one's peers.

An exhaustive coverage of the projects is impossible, however the following section highlights a few examples of playful projects.

\section{$4 \quad$ Playful Projects}

\subsection{Poetry in Motion}

"Poetry in Motion" is an example of a typical first year project that encapsulates a wide range of theoretical and conceptual elements into a unified whole. The project is designed to explicitly embody the concept of play and playfulness whilst implicitly introducing students to a range of design and manufacturing technologies and principles.

The project was inspired by the popular 1960's board game, Mousetrap, in which players cooperate to build a working Rube Goldberg-like mousetrap. Once the mousetrap has been built, players turn against each other and attempt to trap their opponents' mouse-shaped game pieces. In 2006 the game was rereleased with a new design in which there are three mousetraps, and completely different mousetrap mechanism and game play. The project also references artistic works such as "The Way Things Go" by Fischelle and Weiss or Jean Tingley's "Homage to New York" as inspiration. The focus of such works is on the playful and creative sequence of events that trigger each other without any practical purpose in mind. They are mechanisms for mechanism's sake - "art for art's sake". They exploit an innate understanding of physics and a fundamental enjoyment of movement and mechanics. The structure and context of the Poetry in Motion project suggests that "You don't have to be an Engineer to figure it out".

The overall goal of the Poetry in Motion project is to design and create a chain reaction game using imaginative and interesting combinations of basic mechanical systems. Overall, the project is designed to promote risk taking as well as achieve a practical appreciation of principles of physics and mechanics. The project is structured in two parts, the first being the creation of a simple mechanical automata that is designed using CAD software and then manufactured by utilising the laser cutters in the Faculty fabrication facility. This part of the project ensures that students understand that the practicalities of motion of manufactured parts may differ from simulated motion in the CAD software, often in catastrophic ways with mechanisms failing to operate. One aspect of promoting a playful approach to learning and the taking of risks is being prepared to deal with failure. A "failed" project is often a successful learning experience and whilst beyond the scope of this chapter, we embrace the success of learning even when the outcomes of a project may typically be considered a failure [39]. A typical mechanical automata is shown below. 


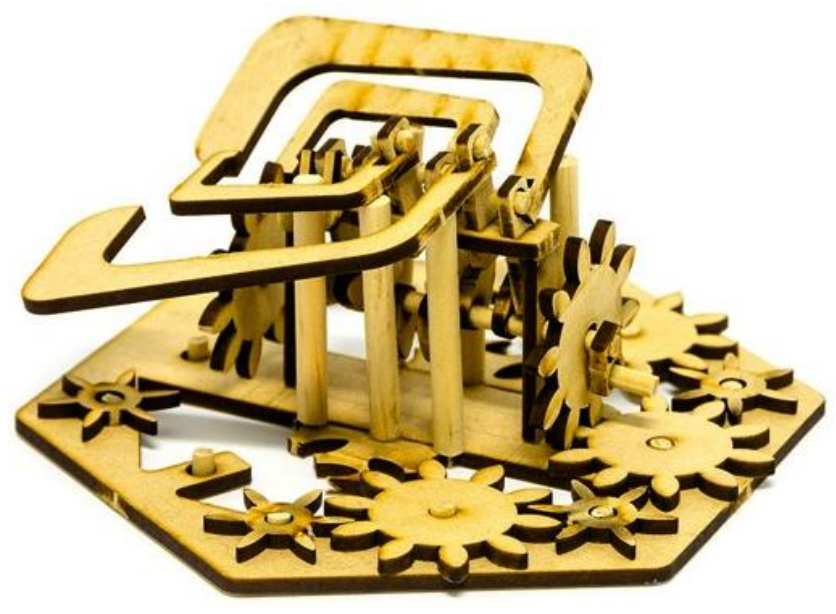

Fig. 1. Sample automata

Upon completion of the first stage of the project, students are encouraged to let their imaginations run wild in the design and implementation of their chain reaction game, applying what they have learned in terms how mechanical systems work in practice in combination with their understanding of the importance of social and co-operative play. The outcomes of the project are predictably variable, with some students successfully using the project to extend themselves into other play selves through the process of an experimental approach to developing play. Some sample student projects are shown in Fig. 2.

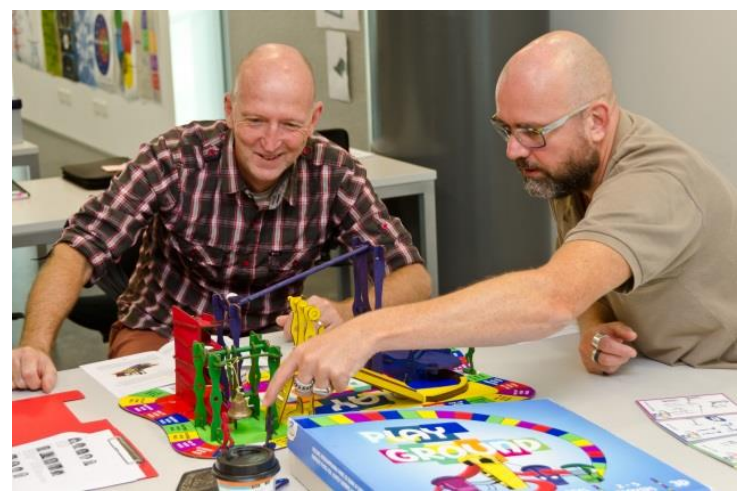

a.

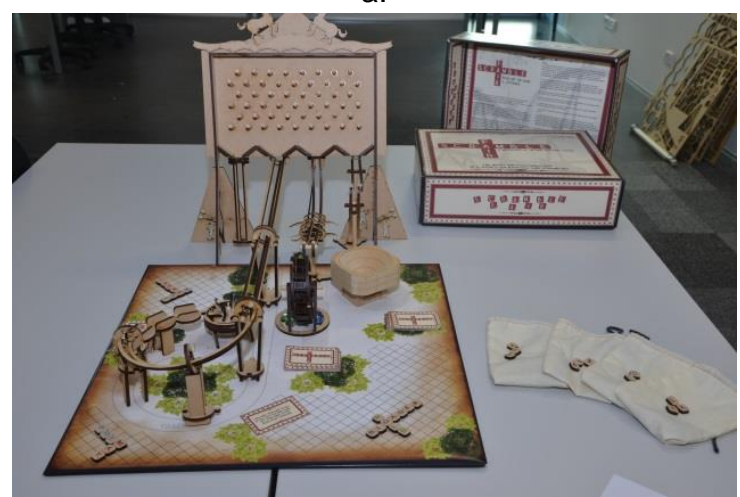

C.

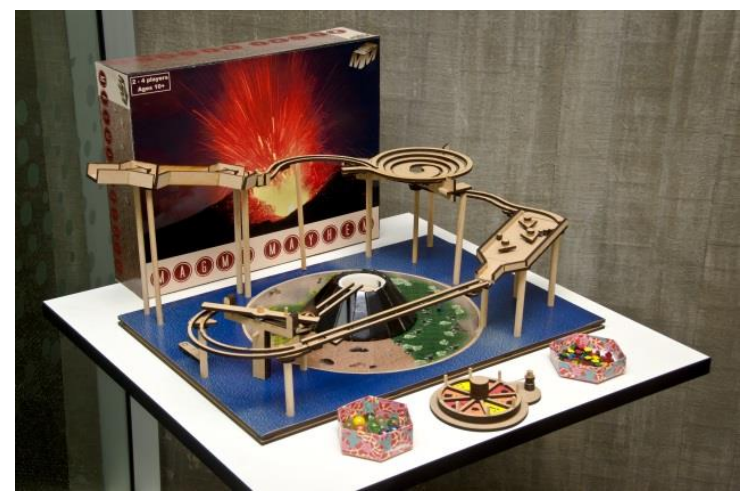

b.

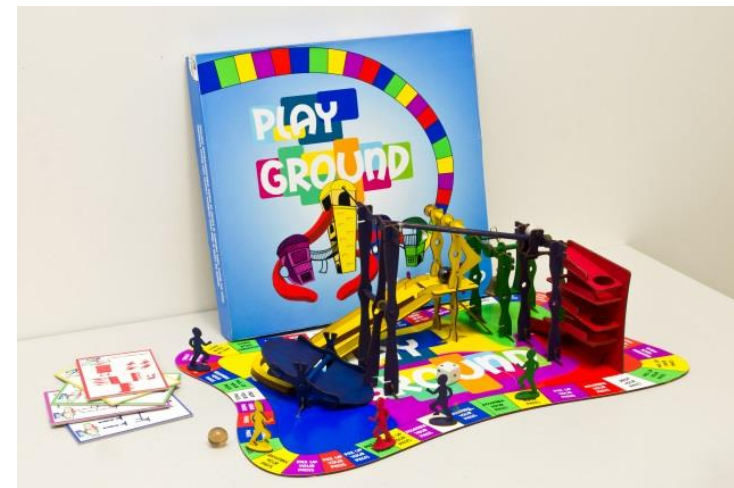

d.

Fig. 2. Sample student projects 


\subsection{Synthesis}

The first year of the BCT degree is to some extent "scripted" by tutors to reduce the likelihood of students becoming lost and unproductive. As students progress to the second year of the degree, such defined projects are removed and replaced with one or more thematic concepts that are used to guide student projects without overly constraining content.

"Synthesis" is an interactive installation developed by a group of second year students to encourage an exploration of synthetic and organic growth within a projected environment. Using emerging technologies, Synthesis aims to engage the audience with an artificial system of interactive construction, and invites participants to become part of the harmony or imbalance created. Images of the installation during preparation and in the final presentation stage are shown in Fig. 3.

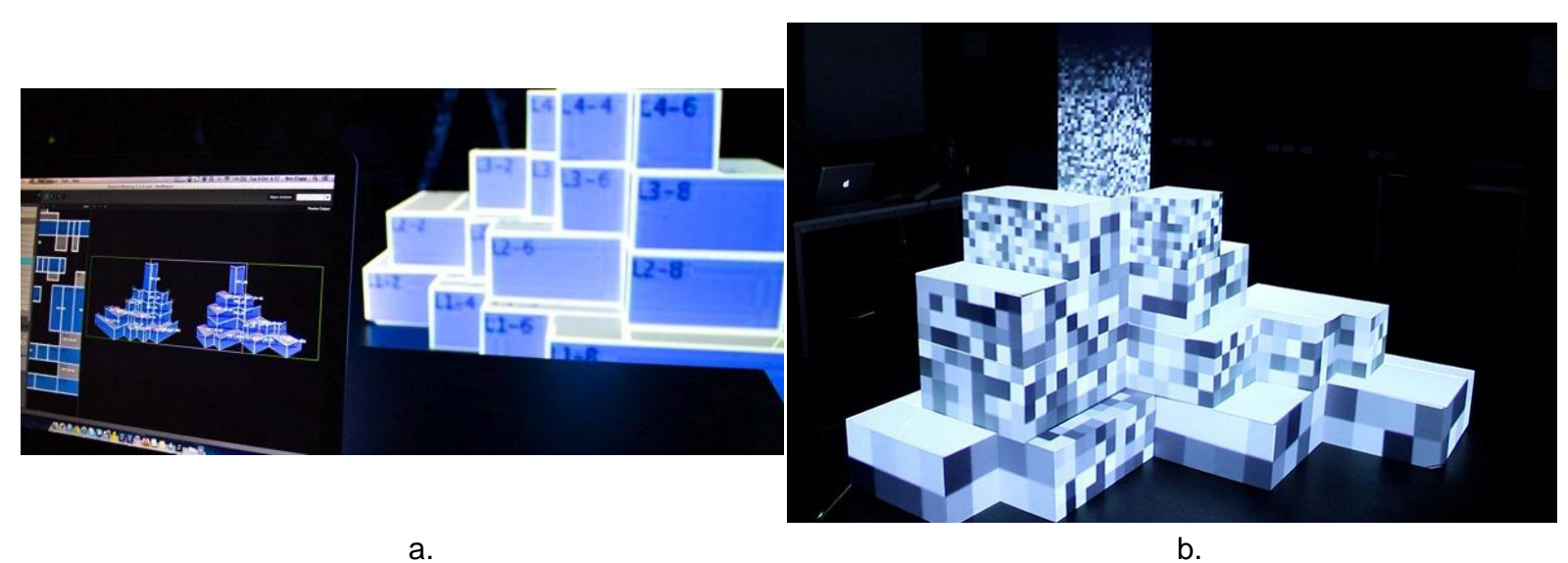

Fig. 3. Project mapped installation - "Synthesis"1

Using a process known as projection mapping, Synthesis harnesses a central free-standing geometric sculpture as a canvas. A video feed is mapped and projected onto the many surfaces of the sculpture, inviting audience members to view the installation from 360 degrees, anywhere in the room. Interaction is registered through Kinect sensors, tracking movement and altering the display accordingly.

Developing within the installation is a planar building block-esque formation representing engineered or synthetic construction, and an organic movement based representation which utilises softer, more flowing aesthetics and palettes. Both are linked to the level of audience interaction; synthetic elements relying on interaction for growth, and organic elements developing in areas with less interaction.

This particular project is of interest in the context of playful creation and engagement as it marks a milestone in the developmental journey of a team of students who formed the collective agency, Fantail Studios, while enrolled in the degree. In terms of the rhetorics of play, this indicated a transition into both play as identity and play as self for the students in the team. This clearly marked the shift into the personal developmental stage which is commonly encountered with students in their second year of study. The team describes their relationship with the installation as:

\footnotetext{
${ }^{1}$ https://www.youtube.com/watch?v=dYjIZ7HTI_w
} 
"As the creators of Synthesis we have a firm personal connection with the ideology of harmony and balance. These key themes were a major influence on the construction of the installation. Although not necessarily goal driven, there is an underlying desire that audience members will explore and observe the way they affect the environment, and the consequences of their interaction. With Synthesis, we hope many personal interpretations are formed, and aim to provide the opportunity for participants to explore the concept of harmony and synthesis for themselves."

The stated intent to have no specific goal in terms of the interaction with the installation implies a degree of playfulness and a faith in the ability of the audience to respond in an equally playful way. This suggests that the team is on the cusp of entering the Sensitive play self, which emphasises interpersonal connectivity by sharing experiences and acknowledging contextual aspects of play. They are clearly aware of the observer and multiple viewpoints as they suggest their installation raises questions regarding the nature of man, and the relationship between humanity and its environment such as "Where does man fit into nature?" and "At what point does something become inorganic?" and suggest that Synthesis demonstrates the relationship between organic and synthetic growth, and therefore gives form to these questions by implementing an experience that enables the observer to play with that form.

\subsection{Guerrilla Playspaces}

Guerilla Playspaces was a semester-long project undertaken by second year students, in partnership with an external civic organisation, the Committee for Auckland (CFA). The group sought to address the aim of the Auckland City Plan to be the 'world's most livable city'. This aim is threatened by the segregation of life between dispersed residential suburbs and the largely commercial districts of the Central Business District (CBD), particularly for certain residential groups such as families and senior citizens. This situation is made worse by Auckland's geography and the challenges of creating a transport system that enables people to move simply and efficiently from the sprawling suburbs to the CBD. As a consequence, many Auckland residents do not identify with the CBD and avoid it if they can. The aim of the project then was to create life, vitality, connection and enjoyment in prominent areas of the CBD where these elements were lacking or not considered possible.

Successful city centres are a melting pot of peoples, cultures and life. They have an energy that is sustaining and regenerative. Despite recent excellent work to improve the quality of the city centre and waterfront spaces, loitering and socialising in the CBD only really occurs as a result of organised events or for short bursts as weekend evening revellers fill the bars and clubs.

Jan Gehl, a renowned urban designer once stated "First life, then spaces, then buildings the other way around never works". Despite the creation of some fantastic new spaces in the city as a result of the shared space and other urban design initiatives, the 'life' that would fill these spaces throughout the day is largely missing.

Multiple teams of students worked on this project to develop different concepts for spaces to create opportunities for play that fundamentally alter people's perception of the CBD as a

\footnotetext{
${ }^{2}$ http://fantailstudios.co
} 
desirable location to live and thrive. The variety of playspaces attests to the diversity of the student cohort and each concept each had a different level of cohesion and resolve. For example, two sub-projects ("Hit the Floor" and "Planter Box") are relatively unsophisticated in their nature, relying on active and passive interaction of passersby to activate the play space. The outcomes of these projects are shown in Fig. 4.

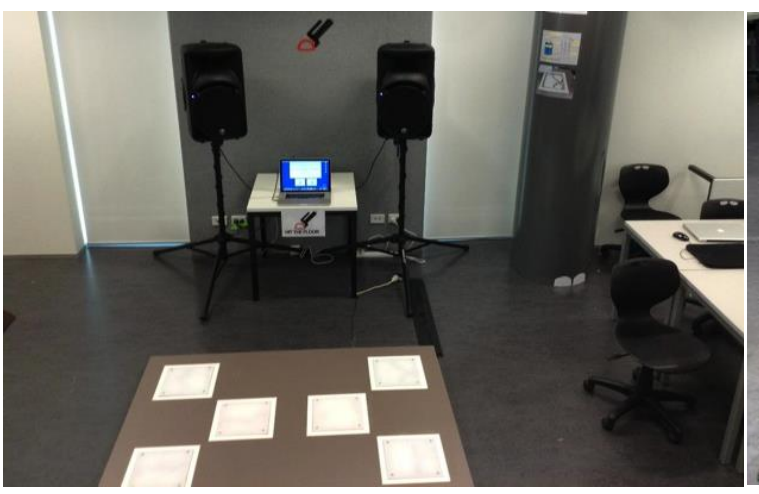

a.

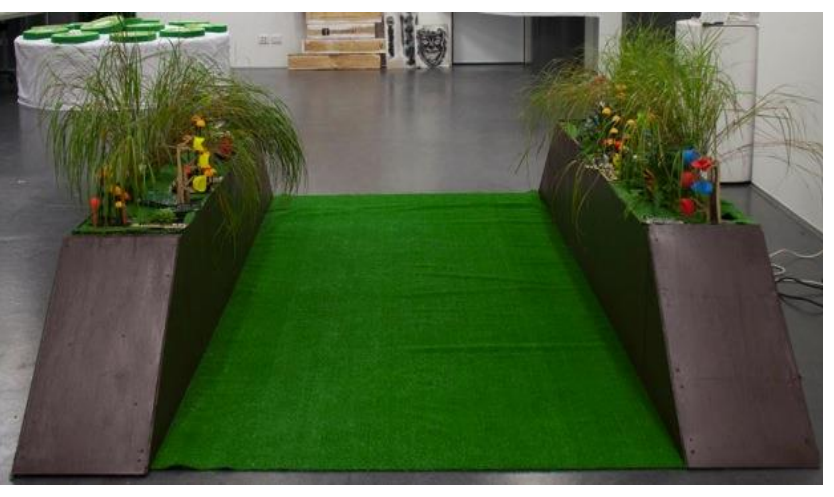

b.

Fig. 4. Hit the Floor and the Planter Box

Meanwhile, another sub-project ("Social Pavlova") incorporates audio feedback based on a behavioural algorithm to allow the space to take on a more sublime living nature. The Social Pavlova is shown in Fig. 5.

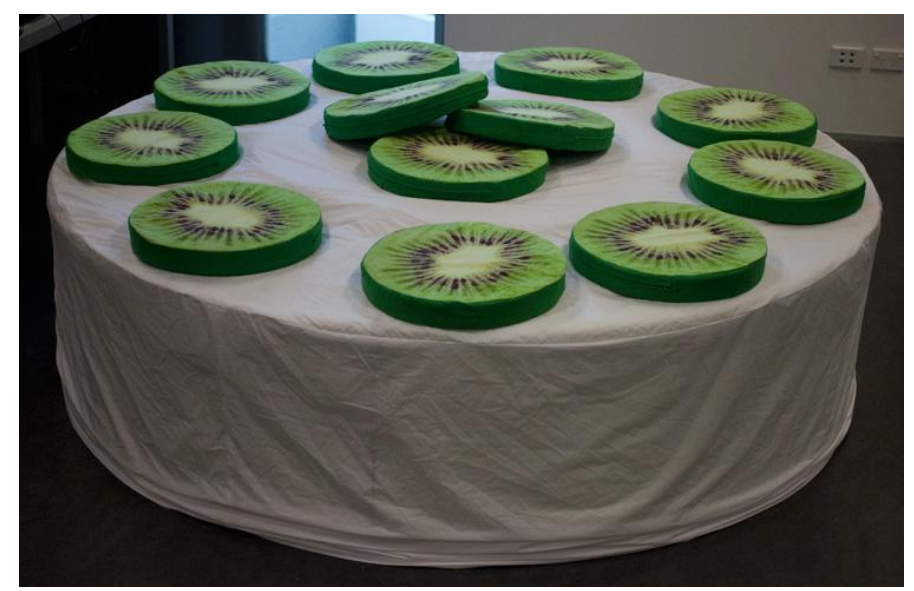

Fig. 5. The Social Pavolva

The adaptive nature of the playspace prevents it from being a simple chair or sculpture and it becomes a living thing within the city. How people interact with it influences how it "feels", and thus how it responds to others. This connects people together through shared experiences across time, as the interactions of one person will affect the mood of the piece for the next person who encounters it. The piece seeks to both draw people in and push them away depending on how it feels. It mediates this interaction through sound, attempting to influence the behaviour of the people who come across it.

The different levels of sophistication and quality of finish in the prototypes are accompanied by a difference in the nature of playfulness exhibited. The less sophisticated projects were developed by groups who very much identified themselves in relation to their peers, a

\footnotetext{
${ }^{3}$ https://www.youtube.com/watch?v=obitExGhY7k

${ }^{4} \mathrm{https}: / / w w w . y o u t u b e . c o m / w a t c h ? v=t 7 q W v P x B \_9 M$
} 
characteristic associated with the Ordered play self. The outcomes of these projects have elements of Play as Imagination, yet the simplistic and deterministic interaction has overtones of the Play as Fate. In terms of development progress, this suggests that the students individually may be at different stages, some pre-personal, some personal and some post-personal and that the tensions that exist between them have implicitly been embedded in the work they produce. The more sophisticated projects, such as the Social Pavolva, have less confusion in terms of classification of the outcomes being clearly associated with the Play as Imagination rhetoric and the Sensitive play self.

When considering both of the previous project examples, Synthesis and Guerrilla Playspaces, it becomes clear the second year of the degree is a period of development and growth for the students with many students clearly reaching the personal stage and moving on to the post-personal stage of development.

\subsection{Virtual Reality Wheelchair Simulator}

The Virtual Reality Wheelchair Simulator is a serious game project developed by five students during a second year "Simulated Environments" paper with the generic topic "Serious Games". At the beginning, students inquired and learned about the topic in general, investigated and developed definitions of "Serious Game", and looked at development and educational frameworks around serious games in general. The lectures were short and concise, merely plotting the outline of the area that the students were then asked to fill out by, e.g., giving seminars about types of serious games, collaborative development of a Wiki, group critique sessions. As assessment, the students were required to build a serious game using a topic and implementation platform of their choice. After having gone through some brainstorming, one of the teams came up with the idea of a wheelchair simulator that uses the Oculus Rift for immersion and an actual wheelchair as an input device. With the help of other Colab staff members and their connections and networks, we were able to actually have a wheelchair "donated" for the project duration, and the game quickly took on form.

Halfway through the semester, the students were given the opportunity to showcase their prototype at Digital NatioNZ $2013^{5}$, a public exhibition about new technologies with a specific focus on New Zealand. Although the learning curve for the project was steep, and the conference deadline was a few weeks before the submission deadline of the paper, the incentive of the conference showcase motivated the students sufficiently that they were able to deliver a fully functional prototype in time. The response of the audience to the wheelchair simulator was very positive, even resulting in a TV interview ${ }^{6}$.

In their blogs, the students afterwards reflected positively on the challenges of this project, that it forced them to deviate from their usual course of more comedic and controversial works, and that it was a great confidence boost to see their works being shown in public ${ }^{7}$. Most of the time, this project was approached in a very playful and fun way, but the students were also aware of the serious applications and the market potential of this project.

With respect to the play rhetoric, this project can be categorised as "Play as imagination", clearly demonstrating the post-personal development stage of the students. The virtual

\footnotetext{
${ }^{5}$ http://digitalnationz.com/

${ }^{6} \mathrm{http}: / /$ www.youtube.com/watch?v=010p9JU6sJw

${ }^{7}$ http://jarnetcreativetech.tumblr.com/post/65752097677/wheelchair-simulators-and-life
} 
shopping centre within the simulator was deliberately designed to demonstrate everyday frustrations of wheelchair users like stairs, narrow doorways, long meandering ways to places, etc. Therefore, the wheelchair simulator assists the user to expand the sense of identity, putting them into a situation that is different from their normal life, forcing them to see the world from another perspective - literally and metaphorically. The images in Fig. 6 show the simulator in use at the Digital NatioNZ event.

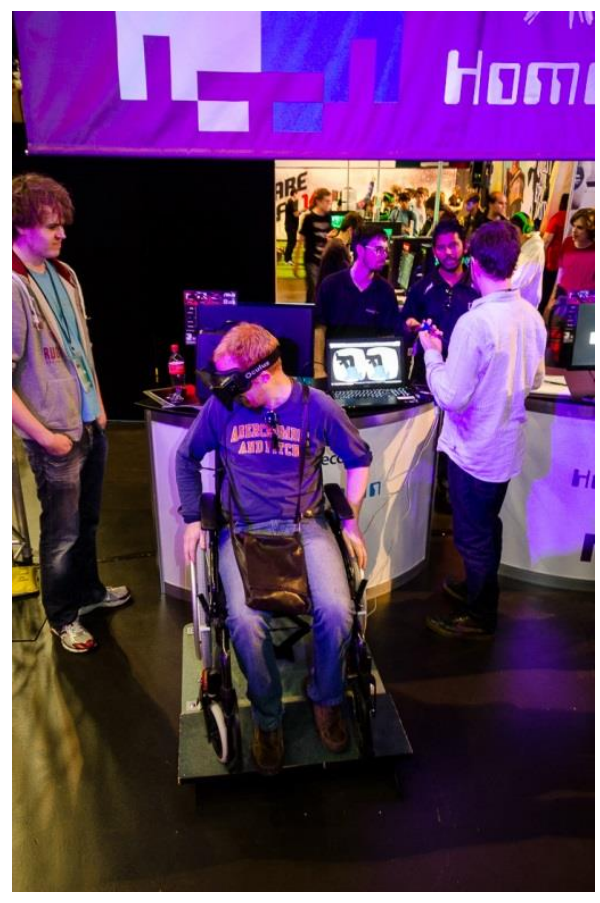

a.

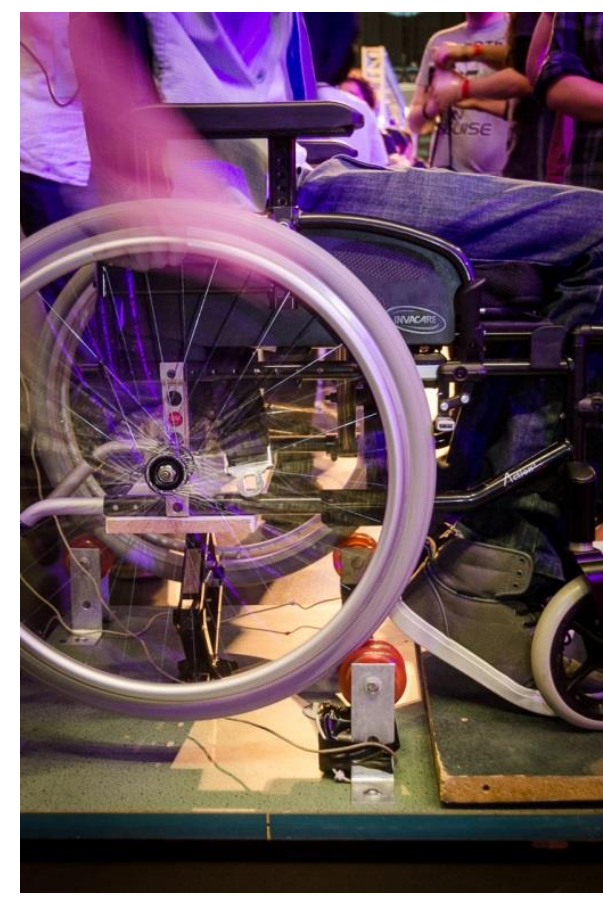

b.

Fig. 6. Virtual Reality Wheelchair Simulator at Digital NatioNZ

\subsection{Lost in a Rift}

"Lost in a Rift" is a third year Studio project that was designed and implemented by three students. The intent was to extend the amount of sensory information for a virtual environment beyond visual and auditory ${ }^{8}$. Using Arduino and a custom circuitry, they connected a fan and a heat-lamp to the computer that run the virtual reality simulation. The students then designed and modeled virtual scenarios with locations and situations that would make the best use of these additional devices. In one scene, the user could feel the wind blowing when they would cross a bridge over a mountain pass. The heat lamp would be activated in a scene where an explosion occurs close to the user, or where the sun is shining.

In order to also facilitate a seamless transition from the real world into the virtual world, the starting and ending scene was modeled in a way that resembled the setup of the physical installation, so the user would find themselves sitting in a chair in a high-rise building, being able to look out of the windows. Navigation was made simple by merely three buttons for walking forwards and turning left and right, conveniently located on the chair's armrest.

Nothing in this project was predefined by lecturers or course content. The project was born from the students' fascination of Virtual Reality and latest technologies like the Oculus Rift

\footnotetext{
${ }^{8}$ http://cargocollective.com/bctyear3catalogue13/Lost-in-a-Rift
} 
and a desire to play with such technologies to see what may emerge. Such an approach is common with final year students who learn through a process of making, rather than having a specific goal in mind. From this starting point, the group developed the whole concept, did the necessary background research, and kept in close contact to the lecturers who would help them in specific aspects, e.g., game engines, electronics, the aspect of "Presence" [40]. Some design decisions even happened by accident, e.g., the idea of the heat-lamp was born during a feedback session where the lecturer happened to sit in the sun shining through the window during a sunny virtual reality scene. The final environment developed by the students is shown in Fig. 7.

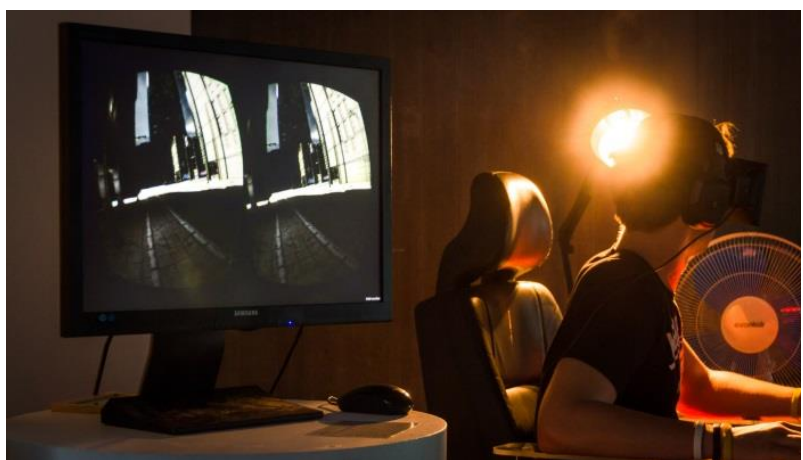

a.

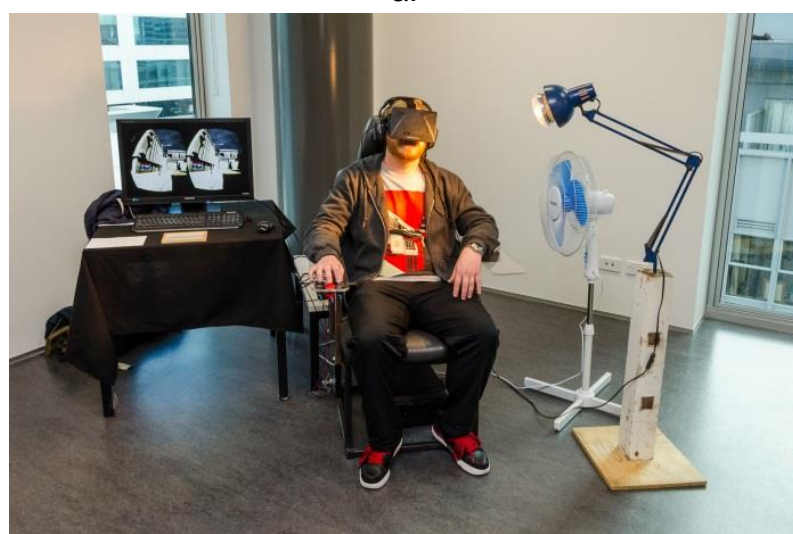

C.

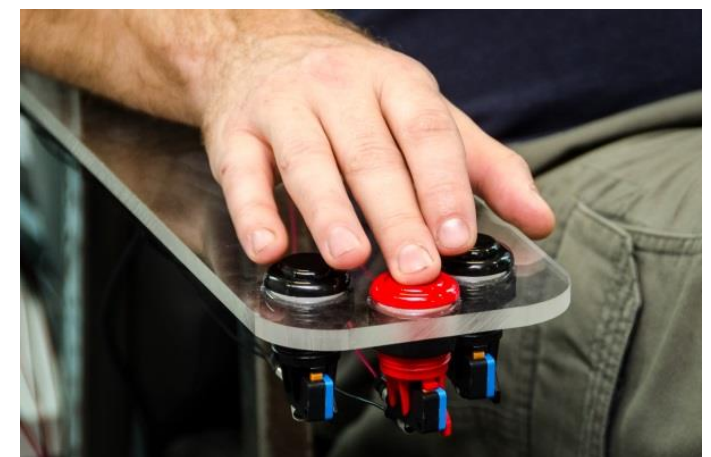

b.

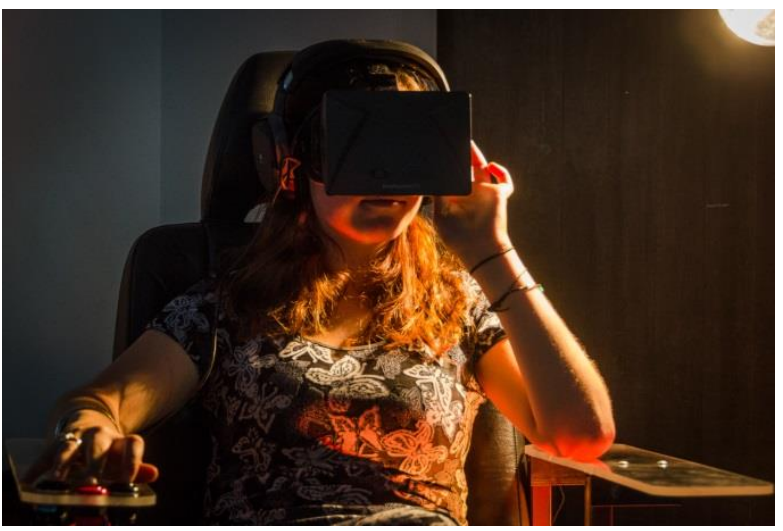

d.

Fig. 7. Lost in a Rift

As with the previous project, this is very much an example of students adopting the play as self rhetoric, using their projects to explore themselves and their interests. Whilst play as self rhetoric is often applied to solitary activities and hobbies or high-risk phenomena like bungee jumping, there is also an element of play as self-realisation [41] which correlates well with elements of the self, particularly where play is idealised by attention to the desirable experiences of the players - their fun, their relaxation and their escape. In this project, the students truly escaped the confines of a more traditional education by having fun whilst exploring their own interests.

\subsection{Rabble Room}

"Rabble Room" is another third year studio project by two students based on the idea of a "social play space" with a focus on "local video games, tangible interfaces and physical fun". It is an example of a student project that extended beyond a single semester and as such is a case study in sustained inquiry.

\footnotetext{
${ }^{9}$ https://www.facebook.com/pages/Rabble-Room/149553558551802
} 
In the first semester, the students experimented with the idea of constructing unconventional physical input devices for games, for example, pulleys or handheld tilt sensors. While they focused mainly on providing the input hardware, they started to commission game developers to provide custom mini games tailored for the provided input devices. The students also developed a classification framework for the characteristics of games and the input devices, e.g., "eight-player one-button". The second semester was largely dominated by the curation and planning of the final event, the "Rabble Room Arcade". Located within the university premises, but open to the public, the event featured 8 very different games:

- "Double Shovel", a game where two players would cooperatively shovel grain into a chute to trigger events like feeding a child or cleaning up a kitchen.

- "Elevator", a two player competitive game with cranks as input devices that have to be operated as fast as possible to make the game character go up an elevator as fast as possible while avoiding virtual objects being thrown at them.

- "Space Octopus Mono", an 8-bit style arcade game where the players control the horizontal position of the spaceship via wooden sliders on wooden rails.

- "Off Da Railz", a game where the player controls a train with a wooden board that has tilt sensors for direction and speed control.

- "CatManDudu", an experimental game controlled by two foot-operated buttons for direction and a toilet chain switch for triggering "shots".

- "Eight-player Word Wars", a competitive game for up to eight players that have form words by "grabbing" letters that appear on the screen by pushing a single button.

- "Fruit Racers", a four player competitive game with rotary encoders as input devices to control the direction of fruit on the screen in a race setting.

- "Shadow Showdown", a cooperative game where one or more players have to match silhouettes on the screen by creating silhouettes with their own body/bodies.

The event was visited by more than 100 people, and also featured on an evening TV show ${ }^{10}$.

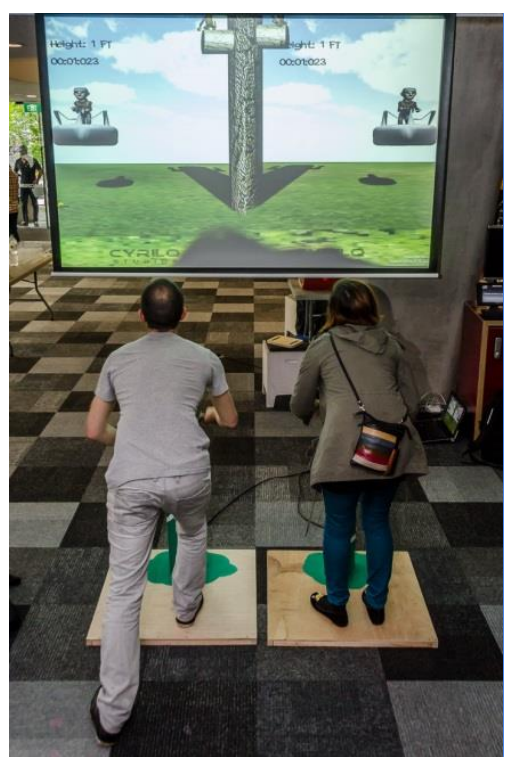

a.

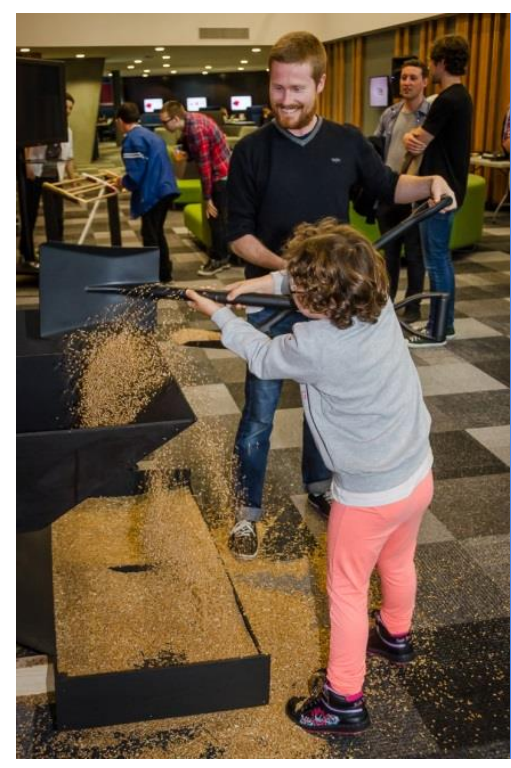

b.

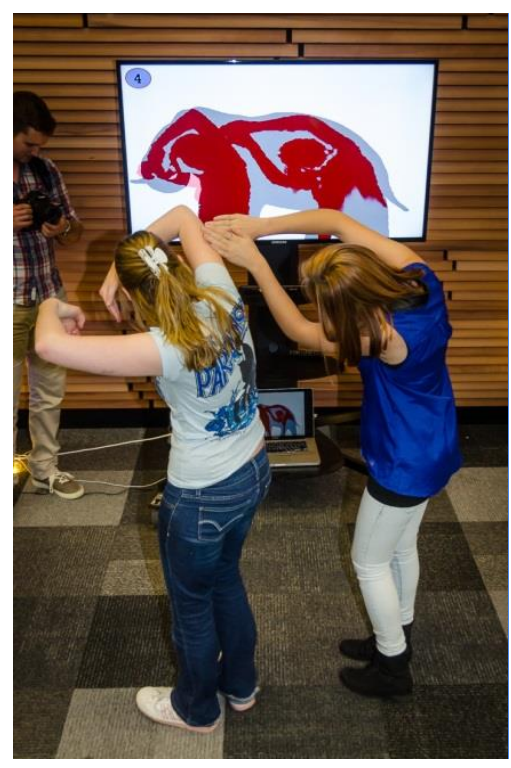

C.

\footnotetext{
${ }^{10}$ http://tvnz.co.nz/seven-sharp/future-gaming-video-5624010
} 


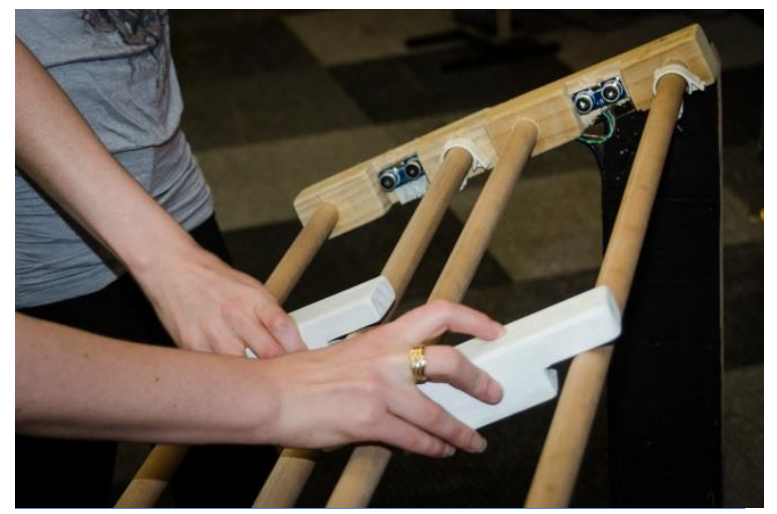

d.

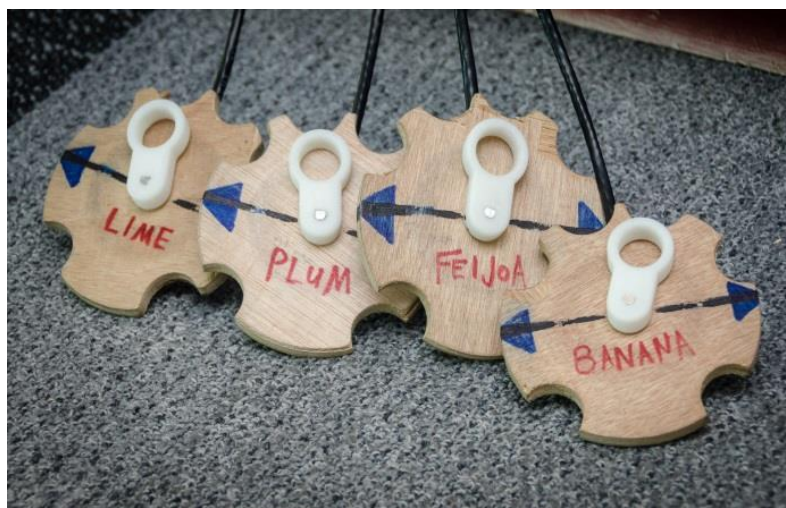

e.

Fig. 8. Rabble Room Arcade

More than any other project considered in this chapter, the Rabble Room project articulates the more developed rhetorics of play. The students are clearly advocating "play for the sake of play" which would be in line with the expectations of the Frivolous Play rhetoric. Not only are the students promoting frivolous play but are simultaneously poking fun at the societal norms associated with game culture and utilising their arcade to enhance social interaction and emphasise the physical importance of play. It is clear that the students are attempting to share their view that the world is a place full of potential and paradox and that this can be explored through a shared play experience. This confirms that these students have also adopted more advanced play selves by demonstrating the capability to integrate multimodal and multidimensional elements across contexts in service of humanity, or in this case a social grouping. Such characteristics would tend to be associated with the Dynamic Player.

\section{SUMMARY: The state of play}

We have described a representative sample of student projects from the BCT degree, all of which exhibit some degree of play or playfulness. While any universal definition of play or playful behaviour remains elusive, an analysis of the projects suggests that as students progress through the degree, the nature and character of their play changes. It is important to emphasise here that we do not present play as a purely instrumental approach to learning. Our observations indicate that students are undergoing a developmental journey that extends their creative capabilities and their potential to contribute to society. Such anecdotal evidence is in accordance with other research that suggests that play can contribute to the social capital of adult learners [4, 42]. Whilst play may seem fanciful, the projects outlined in the previous section can be mapped to the expected characteristics of the graduate profile. A number of generic graduate attributes have been excluded, however the mapping to relevant attributes is shown in Table 2 . Whilst there is only partial coverage, it is important to bear in mind that each project only constitutes a single semester of study. Whilst gaps and anomalies exist, the projects at the higher levels of study show the highest degree of achievement in terms of demonstrating the graduate attributes. This suggests that as students develop through the degree that they are more capable of undertaking work of sufficient scale that it addressed multiple aspects of the graduate profile. Interestingly, few of the projects discussed address issues of sustainability though many other projects not included do consider this. 


\begin{tabular}{|c|c|c|c|c|c|c|}
\hline \multirow[b]{2}{*}{ Graduate Attribute } & \multicolumn{6}{|c|}{ Projects } \\
\hline & 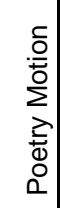 & $\begin{array}{l}\frac{\infty}{\omega} \\
\Phi \\
\stackrel{\Phi}{ \pm} \\
\omega\end{array}$ & 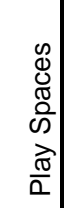 & 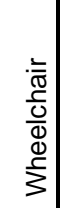 & 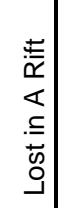 & $\begin{array}{l}\varepsilon \\
\overline{0} \\
\propto \\
\frac{0}{0} \\
\frac{0}{0} \\
\widetilde{0} \\
\widetilde{\simeq}\end{array}$ \\
\hline Work together in transdisciplinary project teams & & $\checkmark$ & $\checkmark$ & $\checkmark$ & $\checkmark$ & $\checkmark$ \\
\hline Embrace multiple creative and technological perspectives & $\checkmark$ & $\checkmark$ & $\checkmark$ & $\checkmark$ & $\checkmark$ & $\checkmark$ \\
\hline Demonstrate skills of self, colleague and task management & $\checkmark$ & $\checkmark$ & $\checkmark$ & $\checkmark$ & $\checkmark$ & $\checkmark$ \\
\hline $\begin{array}{l}\text { Acquire an astute awareness of the technical and commercial contexts of the } \\
\text { creative sector }\end{array}$ & & & $\checkmark$ & & & $\checkmark$ \\
\hline Work within and between a range of interlinking technological domains; & & $\checkmark$ & $\checkmark$ & $\checkmark$ & $\checkmark$ & $\checkmark$ \\
\hline Possess an awareness of new and emerging technologies & & $\checkmark$ & & $\checkmark$ & $\checkmark$ & \\
\hline Scan, select and combine technologies suitable for specific projects & & $\checkmark$ & $\checkmark$ & $\checkmark$ & $\checkmark$ & $\checkmark$ \\
\hline $\begin{array}{l}\text { Communicate with specialists and stakeholders from diverse disciplines and } \\
\text { enterprise levels }\end{array}$ & & & $\checkmark$ & $\checkmark$ & & $\checkmark$ \\
\hline Plan, organise and execute collaborative work & $\checkmark$ & $\checkmark$ & $\checkmark$ & $\checkmark$ & $\checkmark$ & $\checkmark$ \\
\hline Generate ideas, concepts and artefacts encompassing creativity and innovation & $\checkmark$ & $\checkmark$ & $\checkmark$ & $\checkmark$ & $\checkmark$ & $\checkmark$ \\
\hline Use analytical, synthetic and critical perspectives in the generative process & & $\checkmark$ & & $\checkmark$ & & $\checkmark$ \\
\hline Produce elegant solutions to problems & $\checkmark$ & $\checkmark$ & & $\checkmark$ & & $\checkmark^{11}$ \\
\hline Reflect on avenues for future development and improvement & & & & $\checkmark$ & & $\checkmark$ \\
\hline Incorporate a concern for environmental sustainability & & $\checkmark$ & & & & \\
\hline $\begin{array}{l}\text { Base new learning and research on the cumulative knowledge gained during } \\
\text { and after the course of study }\end{array}$ & $\checkmark$ & $\checkmark$ & $\checkmark$ & $\checkmark$ & $\checkmark$ & $\checkmark$ \\
\hline
\end{tabular}

Whilst demonstrating achievement is important, we also encourage students to 'play' with their own university education and test boundaries. Playing with one's own education changes the perspective of learning as being-taught into an active process driven by one's own interest and curiosity. More specifically, we aim to create conditions in which students learn to use play, interaction and games to develop both exploratory and performative ways of operating in the university environment. In this sense, playfulness also develops qualities of perception, differentiation and judgment that often transcend limits set by formal and, for some, somewhat artificial or extrinsic curriculum requirements.

Students are encouraged to take individual and collective responsibility for their own learning as an emergent process of experimentation, exploration and discovery. Learning and play are initiated by tutors, but realised and managed by students themselves. We suggest that a playful approach affords the freedom for learners to take a greater degree of ownership and control over their own learning. The projects above illustrate how this playful methodology

\footnotetext{
${ }^{11}$ In this example, inefficiency and an unfinished aesthetic were design goals and in this context would be considered elegant, even if objectively they are inelegant
} 
has been applied to learning in the emerging, as yet "undisciplined" field of Creative Technologies.

The remaining questions relate to the future of the degree and the ongoing nature of play and playfulness in post-secondary education. Whilst this chapter outlines anecdotal evidence to support that play is indeed a useful mechanism in assisting students develop as individuals, there is a pressing need to maintain momentum and keep abreast of a changing educational arena. Whilst post-secondary play has seen little research activity to date, recent publications suggest that there will be a greater focus in the future. For example, in a recently published volume [43], various authors consider the role of games and social media in aspects of post-secondary education such as the need to maintain or increase enrolments, ensuring the transition from school to college is successful and the ongoing question of the role of technology in the classroom to name but a few. Our experiences support the outcomes of the contributors to this volume; that whilst play and games can be powerful tools for encouraging students to develop, quality projects, the more important focus is ensuring the ability to develop skills while engaging in the game. It is this engagement that is essential in the effective use of games and playful approaches in teaching and learning. In a manner of speaking, educators are faced with a challenge of designing a game that students want to play - the game of learning. In that regard, maintaining playfulness as an educator is as important as promoting playfulness in the students themselves.

\section{References}

1. Hunziga, J., Homo Ludens: A Study of the Play-Element in Culture2000, London: Routledge.

2. Boyer, E.L. and L.D. Mitgang, Building Community: A New Future for Architecture Education and Practice. A Special Report1996: ERIC.

3. Millar, S., The psychology of play1968, Oxford: Penguin.

4. Gordon, G. and S. Esbjörn-Hargens, Are we having fun yet? An exploration of the transformative power of play. Journal of Humanistic Psychology, 2007. 47(2): p. 198-222.

5. Vygotsky, L.S., Play and its role in the mental development of the child. Journal of Russian and East European Psychology, 1967. 5(3): p. 6-18.

6. Russ, S.W., Play, creativity, and adaptive functioning: Implications for play interventions. Journal of Clinical Child Psychology, 1998. 27(4): p. 469-480.

7. Russ, S.W., Play and creativity: Developmental issues. Scandinavian Journal of Educational Research, 2003. 47(3): p. 291-303.

8. Rice, L., Playful learning. Journal for Education in the Built Environment, 2009. 4(2): p. 94-108.

9. Bologh, R.W., On fooling around: a phenomenological analysis of playfulness. The Annals of Phenomenological Sociology, 1976. 1: p. 113-125.

10. Csikszentmihalyi, M. and J. LeFevre, Optimal experience in work and leisure. Journal of personality and social psychology, 1989. 56(5): p. 815-822.

11. Bowman, J.R., Making work play, in Meaningful play, playful meanings, G.A. Fine, Editor 1987, Human Kinetics: Illinois. p. 61-71.

12. Caldwell, C., Adult group play therapy, in Play therapy with adults, C.E. Schaefer, Editor 2003, Wiley: New York. p. 301-316.

13. Göncü, A. and A. Perone, Pretend play as a life-span activity. Topoi, 2005. 24(2): p. 137-147.

14. Piaget, J., The origin of intelligence in the child1953, London: Routledge \& Paul.

15. Bruner, J., The process of education. Cambridge, MA: Harvard Uuniversity Press, 1977.

16. Bruner, J.S., The act of discovery. Harvard educational review, 1961. 31: p. 21-32.

17. Meyer, J. and R. Land, Overcoming barriers to student understanding: Threshold concepts and troublesome knowledge2013, London: Routledge.

18. Cook-Greuter, S.R., Mature ego development: a gateway to ego transcendence? Journal of Adult Development, 2000. 7(4): p. 227-240.

19. Sutton-Smith, B., The ambiguity of play1997, Cambridge, MA: Harvard University Press. 
20. Kasprow, M.C. and B.W. Scotton, A review of transpersonal theory and its application to the practice of psychotherapy. The Journal of psychotherapy practice and research, 1999. 8(1): p. 12.

21. Lee, H. and G. Lee, The National Certificate of Educational Achievement (NCEA);"Fragilehandle with care". New Zealand Annual Review of Education, 2001. 10: p. 5-38.

22. Hall, C., The national qualifications framework green paper: What future for the framework. New Zealand Annual Review of Education, 1997. 7: p. 29-57.

23. Hellner, J., NCEA: A Terrible Beauty is Born. New Zealand Education Review, 2003: p. 6.

24. Connor, A.M., J. Buchan, and K. Petrova. Bridging the research-practice gap in requirements engineering through effective teaching and peer learning. in Information Technology: New Generations, 2009. ITNG'09. Sixth International Conference on. 2009. IEEE.

25. Gamper, M., 'Experimentierkunst' - Geschichte, Themen, Me-tho-den, Theorien, in Experimente in der Künsten. Transmediale Erkundungen in Literatur, Theater, Film, Musik und bildender Kunst, S. Kreuzer, Editor 2012, Transcript: Bielefeld. p. 19-47.

26. Koethen, E., Das Experiment des Findens als Verfahrensweise der Kunst. Gemeinsamkeiten mit - und Differenzen zur - Wissenschaft, in Experimente in der Künsten. Trans $\neg$ mediale Erkundungen in Literatur, Theater, Film, Musik und bildender Kunst, S. Kreuzer, Editor 2012, Transcript: Bielefeld. p. 337-366.

27. Ackermann, E., Piaget's constructivism, Papert's constructionism: What's the difference. Future of learning group publication, 2001. 5(3): p. 438.

28. Dewey, J., Experience and Education1938, Toronto: Collier-MacMillan Canada.

29. Vygotsky, L.S., Mind in Society1978, Cambridge, MA: Harvard University Press.

30. Wenger, E., Communities of practice: Learning, meaning, and identity2008: Cambridge University Press.

31. Abbott, A., Linked Ecologies: States and Universities as Environments for Professions*. Sociological theory, 2005. 23(3): p. 245-274.

32. Consalvo, M. It's no videogame: news commentary and the second gulf war. in Digital Games Research Association (DiGRA). 2003.

33. Avedon, E.M. and B. Sutton-Smith, The study of games1971, New York: Wiley

34. Prensky, M., Digital natives, digital immigrants part 1. On the horizon, 2001. 9(5): p. 1-6.

35. Connor, A.M., M. Martin, and S. Joe, An extensible framework for automatic knowledge extraction from student blogs. International Journal on Integrating Technology in Education, 2014. 3(2): p. 9-18.

36. Beale, R. Blogs, reflective practice and student-centered learning. in Proceedings of the 21st British HCl Group Annual Conference on People and Computers: $\mathrm{HCl}$... but not as we know itVolume 2. 2007. British Computer Society.

37. Schoenfeld, A.H., Toward a theory of teaching-in-context. Issues in Education, 1998. 4: p. 1-94.

38. Cermak-Sassenrath, D. and C. Walker, $S(t)$ imulating interdisciplinarity, in Simulations, Games and Role Play in University Education, C. Nygaard, N. Courtney, and E. Leigh, Editors. 2012, Libri Publishing: Faringdon. p. 139-149.

39. Connor, A.M., et al., An unexpected journey: Experiences of learning through exploration and experimentation, in DesignEd Asia Conference 2014 2014: Hong Kong.

40. Slater, M. and S. Wilbur, A framework for immersive virtual environments (FIVE): Speculations on the role of presence in virtual environments. Presence: Teleoperators and virtual environments, 1997. 6(6): p. 603-616.

41. Henricks, T.S., Play as Self-Realization. American Journal of Play. 6(2).

42. Harris, P. and J. Daley, Exploring the Contribution of Play to Social Capital in Institutional Adult Learning Settings. Australian Journal of Adult Learning, 2008. 48(1): p. 50-70.

43. Tierney, W.G., et al., eds. Postsecondary Play: The Role of Games and Social Media in Higher Education. Tech.Edu: a Hopkins Series on Education and Technology2014, Johns Hopkins University Press: Baltimor. 